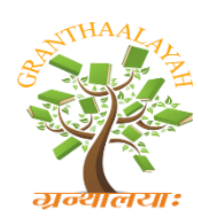
\author{
GRANTHAALAYAH \\ A knowledge Repository
}

INTERNATIONAL JOURNAL OF RESEARCH -

Science

\title{
EXPERIMENTAL METHOD USING ARC WIND TUNNEL TO SIMULATE A NEW TECHNIQUE FOR COMMUNICATING WITH A REENTRY PROBE HAVING A THERMAL SHIELD MADE OF LATS MATERIALS
}

\author{
Sidi Ahmed Bendoukha ${ }^{* 1}$, Kei-Ichi Okuyama ${ }^{2}$, Bianca Szasz ${ }^{3}$, Takayuki Shimoda ${ }^{4}$ \\ *1,2,3 Applied Sciences and Integrated System Engineering, Kyushu Institute of Technology, \\ 1-1 Sensui-cho, Tobata Ward, Kitakyushu, Fukuoka Prefecture 804-0015, Japan \\ ${ }^{4}$ JAXA/ISAS Institute of Space and Aeronautical Sciences, 3-1-1 Yoshinodai, Chuo-ku, \\ Sagamihara City, Kanagawa Prefecture 252-5210, Japan
}

DOI: https://doi.org/10.29121/granthaalayah.v5.i2.2017.1696

\begin{abstract}
Entering a planetary atmosphere is one of the most claim missions as the space probe faces a loss of communication, acknowledged as communication blackout, due to the plasma sheath occurred, caused by temperatures of several thousand degrees in front of the space probe. This paper presents a study about a new method of communication called end of radio silence using the arc heating facilities of Japan. The purpose of the experiment was to test a heat shield equipped with transmitter placed behind it, in a plasma flow of high enthalpy. A receiver was installed in the shroud of the vacuum chamber, protected from the hot gas. Another purpose was to study the behavior of a new type of ablative materials called LATS (Light-weight Ablator Series for Transfer Vehicle Systems) for protecting the space probe against severe heating. The experiment was carried out by using LATS, placed in front of the transmitter for several megawatts per square meter of heat flux. The main measured data are the surface temperature, the thermal performances like mass recession rate, the temperature of transmitter and the electrical parameters as received signal strength indicator RSSI.
\end{abstract}

Keywords: Ablative Material; Heating Test; Communication; Surface Temperature; Mass Recession Rate; Density; Radio Frequency; Reentry.

Cite This Article: Sidi Ahmed Bendoukha, Kei-Ichi Okuyama, Bianca Szasz, and Takayuki Shimoda. (2017). "EXPERIMENTAL METHOD USING ARC WIND TUNNEL TO SIMULATE A NEW TECHNIQUE FOR COMMUNICATING WITH A REENTRY PROBE HAVING A THERMAL SHIELD MADE OF LATS MATERIALS." International Journal of Research - Granthaalayah, 5(2), 1-12. https://doi.org/10.29121/granthaalayah.v5.i2.2017.1696. 


\section{Introduction}

The reentry phenomena depend strongly on the reentry trajectory and the heat shield material composition. The heat shield ablation creates a plasma sheath around the probe in the stagnation point, caused by high heat flux, high surface temperature and speed. However, the wave propagation was attenuated because of the communication losses during the blackout communication since the plasma frequency is much greater than the operation frequency [1]. Some of the prevalent contests related to the space missions were the severe thermal environment of space probe and the radio frequency (RF) blackout during the atmospheric reentry.

The goal of this study is to present the two aspects, the one associated to the validation of the ablative materials [2] called LATS (Light-weight Ablator Series for Transport Vehicle Systems) made by Carbon Fiber Reinforced Plastic (CFRP) for protecting the probe against the harsh heating and for protecting the transceiver from the high in-depth temperature to achieve the range operation temperature. The ablative materials are commonly used as thermal shield were developed by Professor Kei-ichi Okuyama laboratory [3]. The LATS material contains a resin that undergoes thermal decomposition during the heating test.

The other new aspect developed first time, is related to the radio frequency (RF) blackout reentry and consists in testing a device, covered by a heat shield. It is a transmitter (TX) with band frequency of $2.4 \mathrm{GHz}$ located behind the thermal shield which faces a plasma flow heated to numerous thousand degrees. The receiver (RX) equipped with wire antenna was installed in the shroud of vacuum chamber and outside of the hot gas flow to receive the radio signals during the transmission to achieve the received signal strength signal (RSSI), current noise and quality of signal. The both studies are contributing in enhancing the knowledge and in evolving new technologies related to a future small space probe mission, led by universities. This method was established the first time in Okuyama laboratory and also just numerical simulations in German Aerospace center DLR using pulsed electric fields.

The measured data of the tests at Japan Ultra High Temperature Material Center in Sagamihara (JUTEM) and Japan Aerospace Exploration Agency/Institute of Space and Aeronautical Sciences (JAXA/ISAS) are done to measure some parameters as surface temperature, in-depth temperature and mass recession rate of the material to prove that it has good properties for thermal protection [4]. Moreover, the temperature of transceiver and the electrical parameters for room temperature were compared with those measured during the test.

\section{Arc Wind Tunnel Facilities}

The facility has been built for studying the behavior of the thermal protection material and for basic education of the re-entering space probes [5]. The arc heating machine [6] which tests the recession of material surface by blowing a gas, heated to ultrahigh temperature, to the specimen, at high speed. The facilities used for the experiments [7], are mentioned below in Fig. 1 and Fig. 2. 


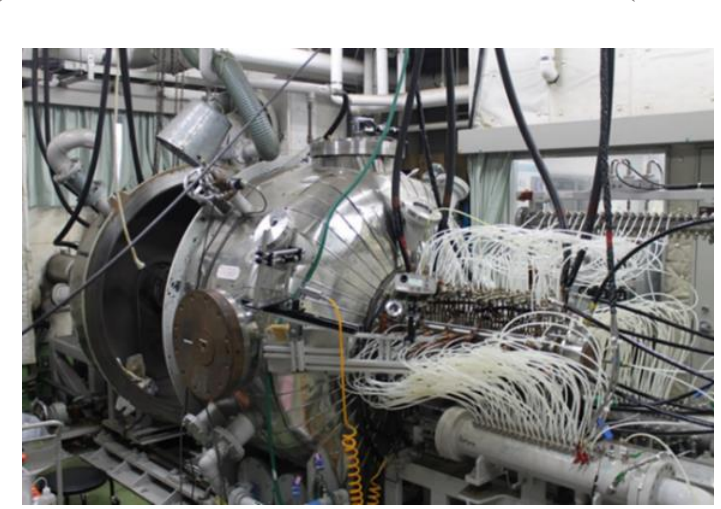

Figure 1: Arc heating test of JAXA/ISAS

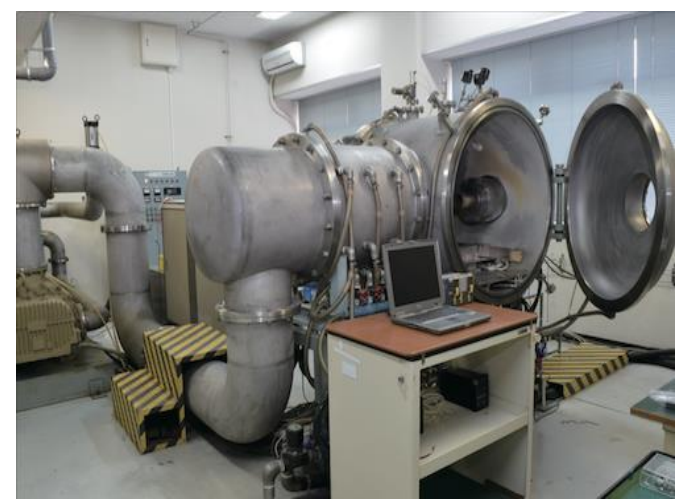

Figure 2: Erosion testing machine of JUTEM

The specifications of the arc heating machines [8] are defined in Table 1.

Table 1: Specifications of JUTEM and JAXA/ISAS facilities

\begin{tabular}{lll}
\hline Specifications & JUTEM & $\underline{\text { JAXA/ISAS }}$ \\
Heating method & Arc heating & Arc heating \\
Heat Flux & Maximum $2 \mathrm{MW} / \mathrm{m}^{2}$ & Max $15 \mathrm{MW} / \mathrm{m}^{2}$ \\
Gases type & Nitrogen $\left(\mathrm{N}_{2}\right)$, Oxygen $\left(O_{2}\right)$ & Air \\
Max input power & $20 \mathrm{KW}$ & $1 \mathrm{MW}$ \\
Discharge Current & 100 to 500 Amperes & 300 to 700 \\
Impact pressure & 0.05 to $0.35 \mathrm{~kg} / \mathrm{cm}^{2}$ & Amperes \\
\hline
\end{tabular}

\section{Methods and Experiments}

For solving problem, several approaches were developed to calculate the temperature of body, the surface recession caused by chemical ablation and received signal strength indicator of transceiver using the arc-jet heaters, are often used to simulate re-entry conditions. The aims of the arc heating tests were:

- To study the thermal performances of the specimen's LATS material for several heat fluxes

- To study the re-entry blackout transmission signal during the arc heating tests. 


\subsection{The Test Models}

The Table 2 defined the variety of the specimens used for the test. The types A, B, C ( $29 \mathrm{~mm}$ of diameter) were used as simple models and $\mathrm{D}$ types $(45 \mathrm{~mm}$ of diameter) were used for the communication tests (COM models), each model having 2D LATS cylinder shape with different densities.

Table 2: The test models

\begin{tabular}{ccc}
\hline Model & Material & Density $\left(\mathbf{g} / \mathbf{c m}^{\mathbf{3}}\right)$ \\
\cline { 2 - 3 } A1 & LATS & 0.3 \\
B1 & LATS & 0.5 \\
C1 & LATS & 0.7 \\
A2 & LATS & 0.3 \\
B2 & LATS & 0.5 \\
C2 & LATS & 0.7 \\
A3 & LATS & 0.3 \\
B3 & LATS & 0.5 \\
C3 & LATS & 0.7 \\
A4 & LATS & 0.3 \\
B4 & LATS & 0.5 \\
C4 & LATS & 0.7 \\
A5 & LATS & 0.3 \\
B5 & LATS & 0.5 \\
C5 & LATS & 0.7 \\
A6 & LATS & 0.3 \\
B6 & LATS & 0.5 \\
C6 & LATS & 0.7 \\
D1 & LATS & 0.7 \\
D2 & LATS & 0.7 \\
D3 & LATS & 0.7 \\
D4 & LATS & 0.7 \\
D5 & LATS & 0.7 \\
\hline
\end{tabular}

\subsection{The Ablator Specimens}

The ablators which were used in this study were designed by CAD software. In order to prevent the lateral sides of the ablator specimen against the high heat, the test piece is covered with a Bakelite sleeve ( $2.5 \mathrm{~mm}$ of thickness). The thermocouples were installed for measuring the indepth temperatures during the test, in the direction of the heat flow. The CAD model is shown in Fig. 3. 

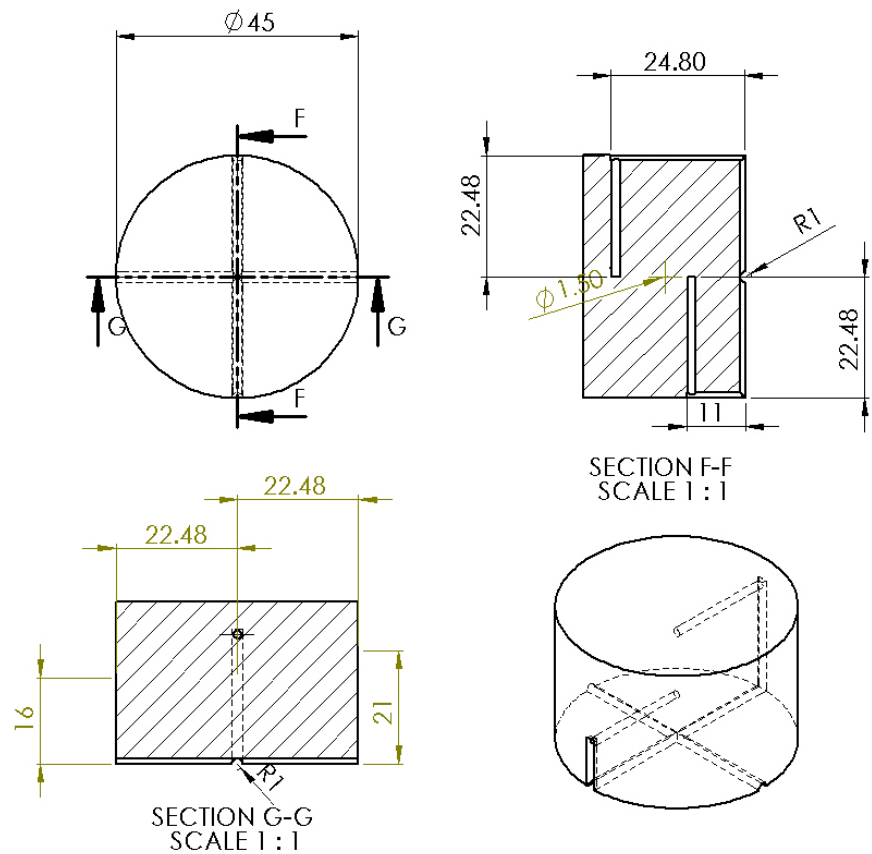

SECTION F-F
SCALE $1: 1$

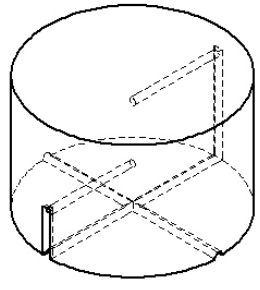

Figure 3: Ablator specimen for communication test

Fig. 4 shows the real model type with pins connection of TX used for the test.
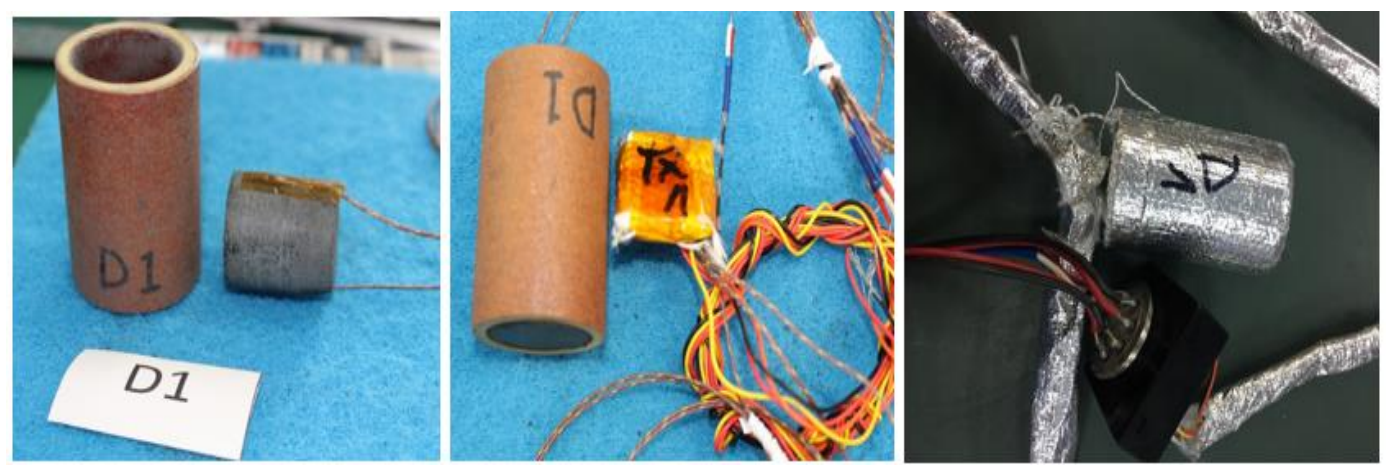

Figure 4: Example of ablator type D1 before test

\subsection{The Tests Conditions/ Test Matrix}

The surface temperature is measured using an infrared pyrometer, which is a sensor that detects the infrared radiation from the surface of the material. The test matrix, flow conditions for each test, is given in Table 3 .

Table 3: The test conditions

\begin{tabular}{|c|c|c|c|c|c|}
\hline Models & $\frac{\text { Heat time }}{\underline{\text { (second) }}}$ & $\frac{\text { Heat Flux }}{\left(\mathrm{MW} / \mathrm{m}^{2}\right)}$ & $\frac{\text { Numbe }}{\frac{\text { rof }}{\underline{\text { TCs }}}}$ & $\underline{\text { Gas }}$ & 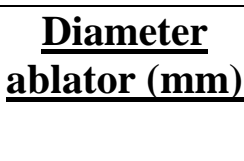 \\
\hline A1 & 120 & 1.2 & 2 & AIR & 29 \\
\hline B1 & 120 & 1.2 & 2 & AIR & 29 \\
\hline
\end{tabular}




\begin{tabular}{llllll}
\hline C1 & 120 & 1.2 & 2 & AIR & 29 \\
A2 & 120 & 0.2 & 2 & AIR & 29 \\
B2 & 120 & 0.2 & 2 & AIR & 29 \\
C2 & 120 & 0.2 & 2 & AIR & 29 \\
A3 & 120 & 1.0 & 2 & AIR & 29 \\
B3 & 120 & 1.0 & 2 & AIR & 29 \\
C3 & 120 & 1.0 & 2 & AIR & 29 \\
A4 & 120 & 0.4 & 2 & AIR & 29 \\
B4 & 120 & 0.4 & 2 & AIR & 29 \\
C4 & 120 & 0.4 & 2 & AIR & 29 \\
A5 & 120 & 0.8 & 2 & AIR & 29 \\
B5 & 120 & 0.8 & 2 & AIR & 29 \\
C5 & 120 & 0.8 & 2 & AIR & 29 \\
A6 & 120 & 0.6 & 2 & AIR & 29 \\
B6 & 120 & 0.6 & 2 & AIR & 29 \\
C6 & 120 & 0.6 & 2 & AIR \\
D1 & 300 & 0.8 & 4 & AIR \\
D2 & 300 & 1.0 & 4 & AIR \\
D3 & 300 & 0.6 & 4 & AIR \\
D4 & 30 & 2.3 & 4 & AIR \\
D5 & 60 & 2.3 & 4 & AIR & 45 \\
\hline
\end{tabular}

\subsection{Communication Diagram}

The goal of the arc heating tests to achieve and evaluate the performance of the ultra-lightweight ablator used for COM models. The key of the experiment for preventing the re-entry blackout transmission signal and if the propagate wave operation (frequency $2,4 \mathrm{GHz}$ ) cross wave signal of heated plasma flow during the heating in chamber, the specimen model (assembly) and conceptual block diagram defined in Fig. 5 and Fig. 6.

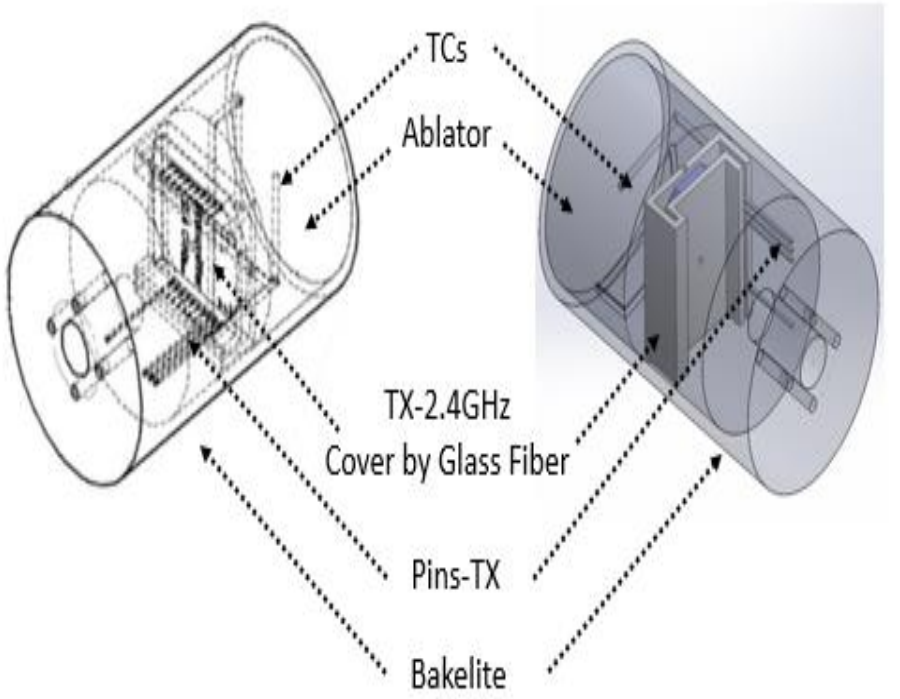

Figure 5: Assembly of the specimen communication model 


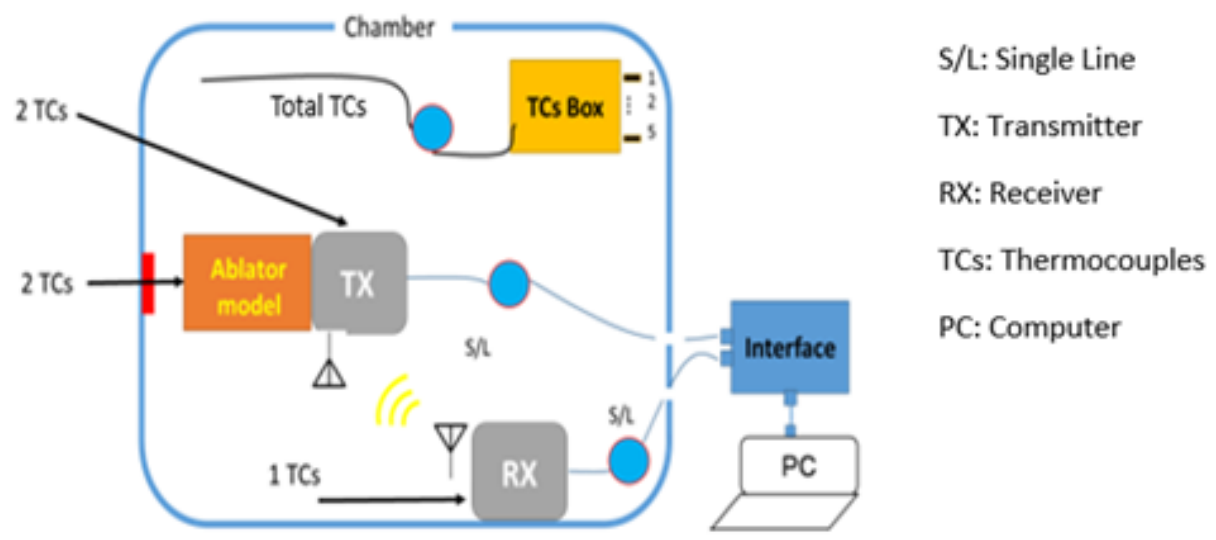

Figure 6: Communication block diagram

Before starting the experiment, the model was fixed by varying the distance from the nozzle and the currents generated by the arc heating machine to select the precise value of heat flux used for each specimen model shape for the runs described in Fig. 7.

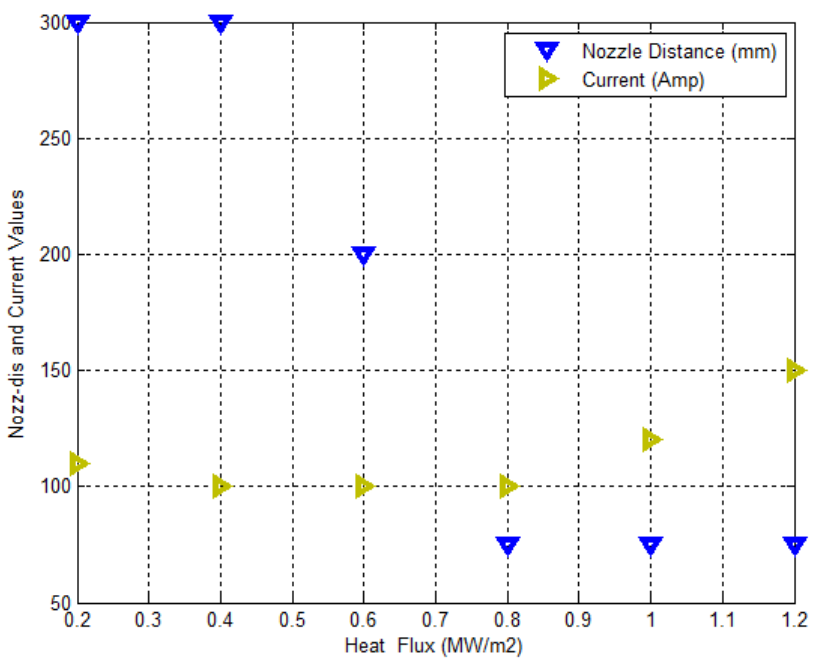

Figure 7: Nozzle distance and current versus heat flux

Fig. 8 shows the specimen model during the test in vacuum chamber.
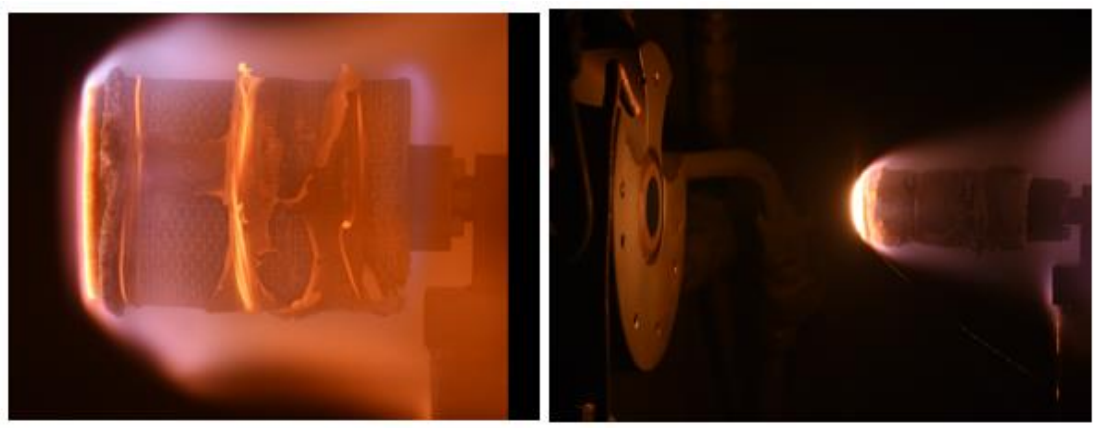

Figure 8: Specimen model during the test heating 


\section{Results and Discussions}

The results of the tests performed at JAXA/ISAS and JUTEM are described in the figures below. The Fig. 9 shows the aspect of the ablator material after heating with high enthalpy.

An empirical relationship between the mass recession rate, density and surface temperature could be found, after analysing the results from the different runs. Also, the values for the communication models appear in Fig. 10, Fig. 11and Fig. 12.
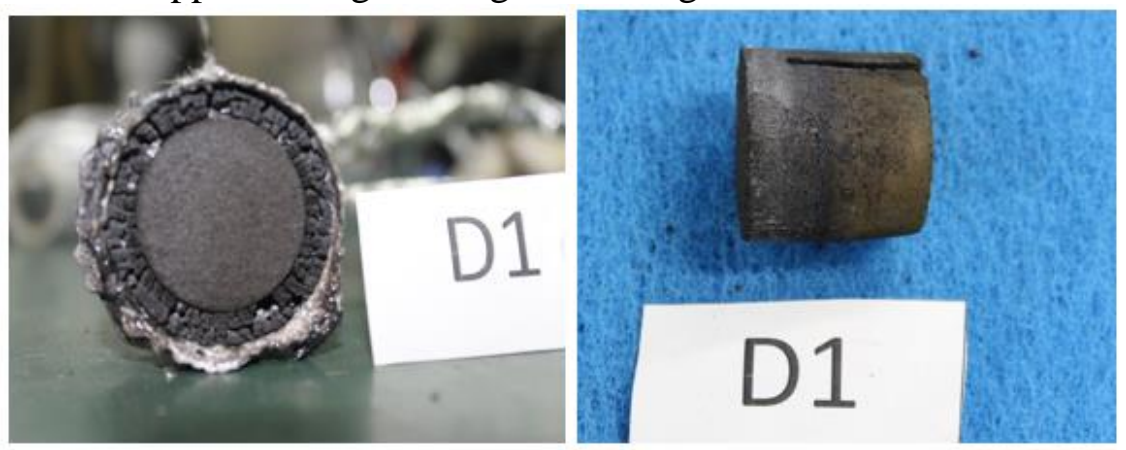

Figure 9: Example of ablator type D1 after test

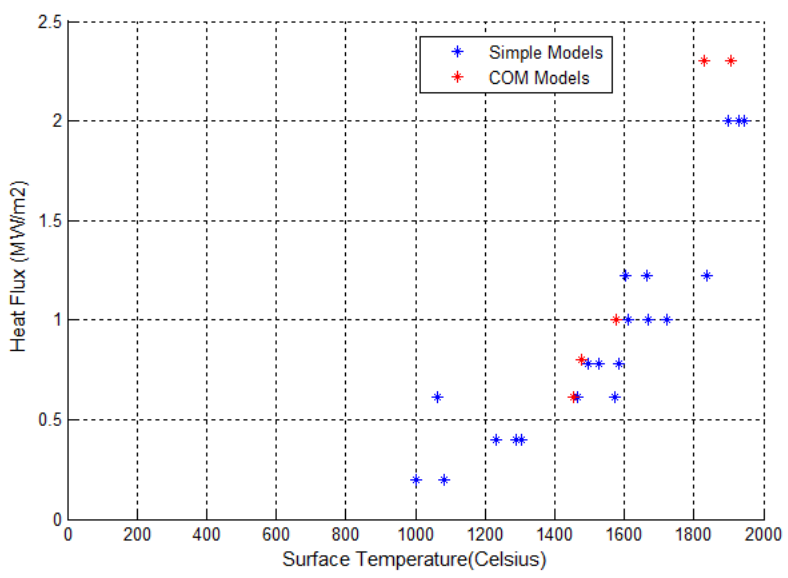

Figure 10: Heat flux versus surface temperature for all models

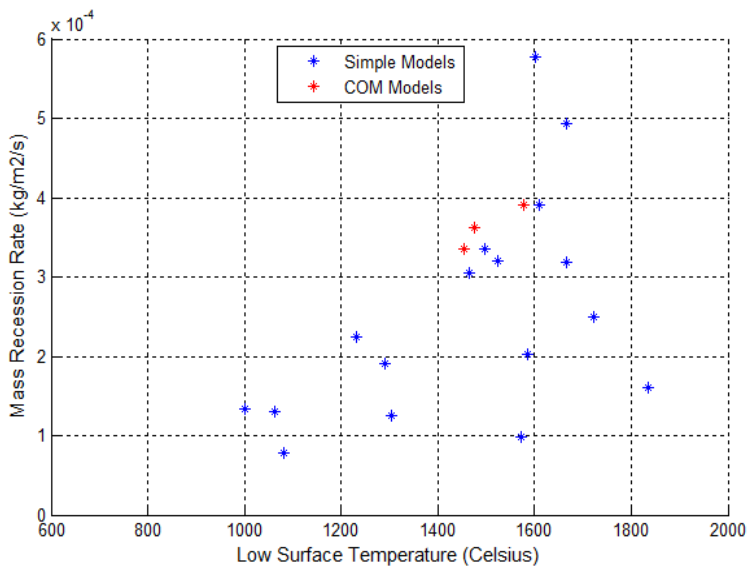

Figure 11: Mass recession rate versus surface temperature 


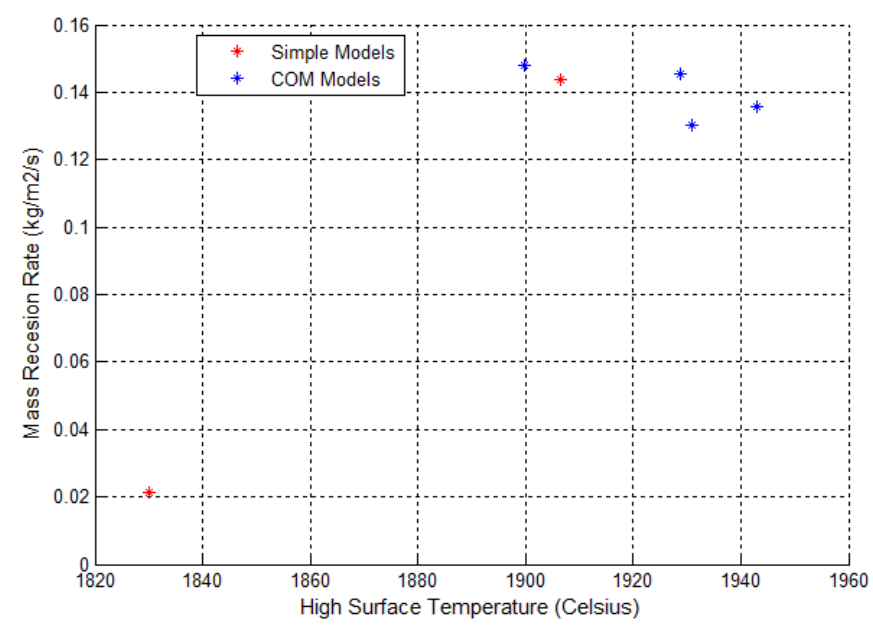

Figure 12: Mass recession rate versus surface temperature

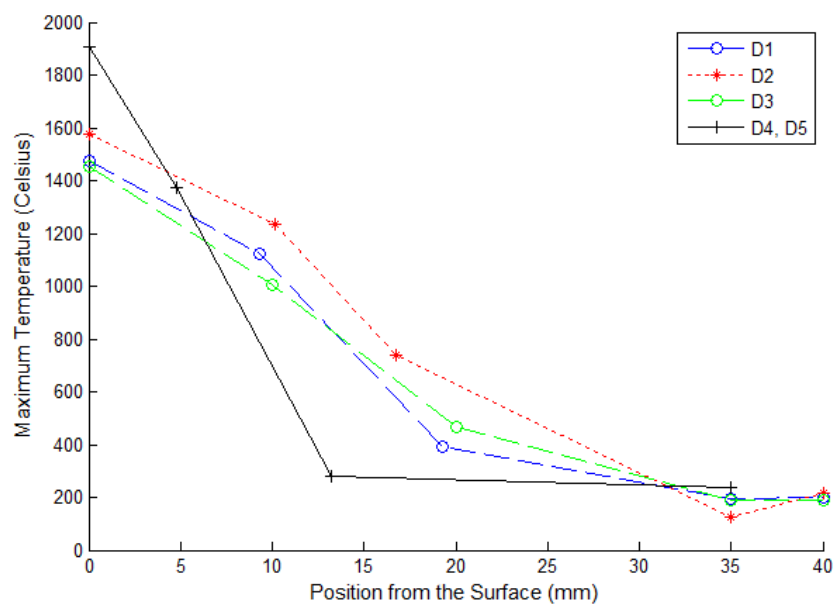

Figure 13: Temperature versus position from surface of the thermocouples

The Fig. 13 presents the results of maximum temperature variation in function to the position from the surface of the thermocouples, in case of COM models.

The measured data are plotted. For example, the Fig. 14 presents the measured results of D1 model for heat flux about $0.8 \mathrm{MW} / \mathrm{m} 2$, describes the time history of in-depth temperature for the TC1 $(10 \mathrm{~mm})$, TC2 $(20 \mathrm{~mm})$. The temperature of transmitter (Tx Temp) and the temperature of antenna (Ant Temp) reached the maximum value about 200 degree Celsius. At this value the TX stopped the transmission of packet, because TX can work in the range temperature about -20 to 120 degree Celsius. From 400 seconds to 800 seconds, the transmitter can work typically and sent the packets during the heating. The communication link can be established for lower temperature and low plasma density (attenuation of signal decrease gradually) related to the impact pressure of vacuum chamber. 

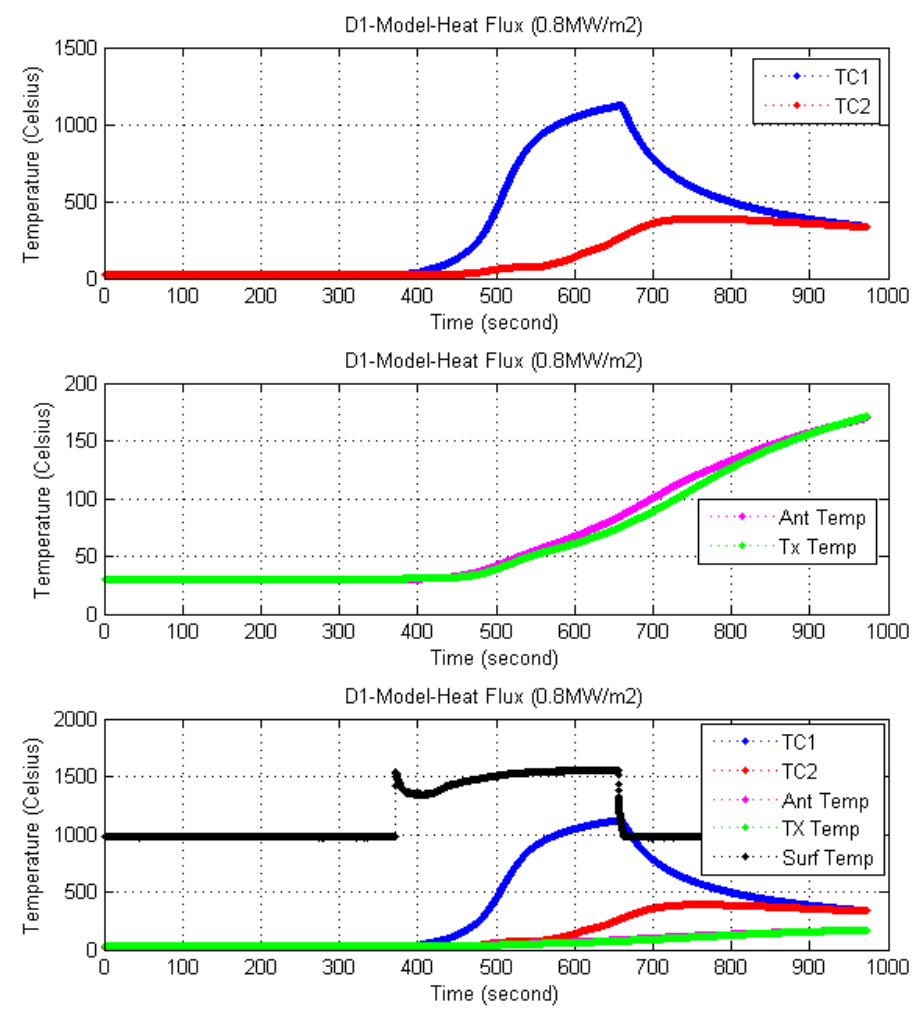

Figure 14: In-depth temperature results of ablator (TC1-10mm, TC2-20mm) and transmitter

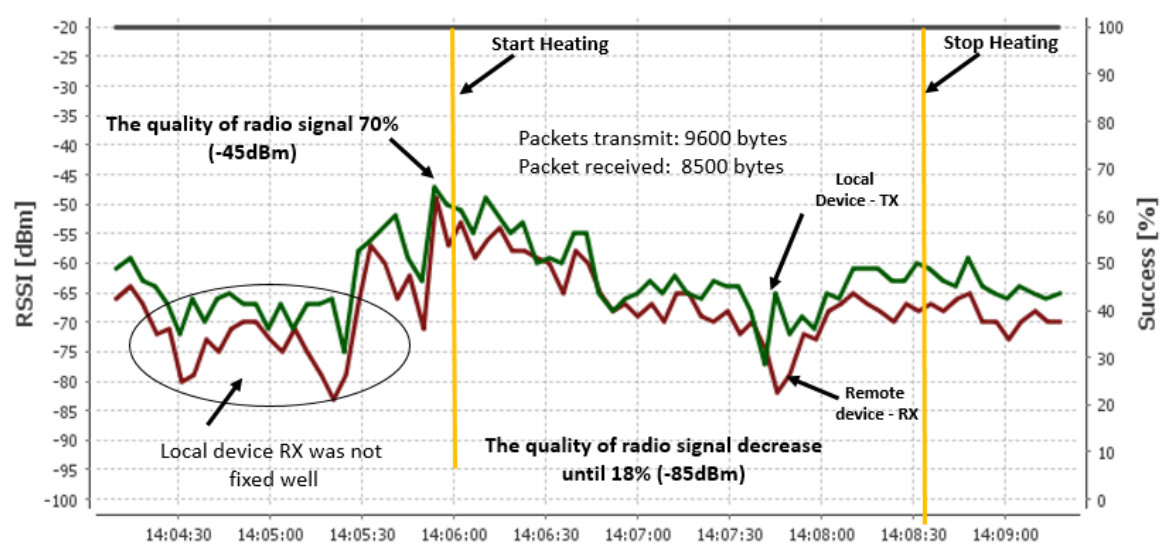

Figure 15: Received signal strength of transceiver (TX, RX) during the test

Finally, to conclude the results, the Fig. 15 defines the RSSI performance during the communication loop (bit rate 9.6 kilobits per second). When the plasma occurred, at the start heating point, the RSSI value was about $-45 \mathrm{dBm}$ (quality of signal $70 \%$ success), after 150 seconds the quality of signal decrease to $-85 \mathrm{dBm}$ ( $20 \%$ of success - communication blackout). To keep the local device (TX) transmit the packets to the remote device (RX), the frequency band should increase because the plasma frequency in chamber is higher than the operation 
frequency and other solution is to use ablator material with high density to reach lower surface temperature.

\section{Conclusions \& Recommendations}

A new method of this study has been developed and it consists in using ablative materials in high temperature conditions. Also, is the first tests executed to achieve the end of radio signal during re-entry phase through the LATS materials developed at Okuyama laboratory. The results proved that the ablator materials with high density $\left(0.7 \mathrm{~g} / \mathrm{cm}^{3}\right)$ used for Com models have a good performances to protect the device (TX) used for the test placed in wake region. Having high density ablative materials mean to have lower temperature and lower mass recession. For the upcoming tests, it is better to increase the density value to $1.5 \mathrm{~g} / \mathrm{cm}^{3}$.

To reach a good result in future, it is better to apply the same method for communicating with spacecraft by adding the magnet field with high intensity between the ablator model and transmitter to reduce the plasma density of vacuum chamber, because the impact pressure was high about 13Torr (1734 Pascal). The new mitigation technique permits to receive more packets during the RF blackout communication (good quality of signal) and to test other types of the ablator materials as Phenolic Impregnated Carbon Ablator PICA made by National Aeronautics and Space Administration (NASA) or hybrid LATS with high density. The method will be applied to innovative thermal protection system in course of improvement to design aero-thermal and to solve the RF blackout re-entry tests in plasma wind tunnel facilities.

\section{Acknowledgements}

This research was supported by the Japan Aerospace Exploration Agency (JAXA), Institute of Space and Aeronautical Sciences ISAS and Japan Ultra High Temperature Material Center in Sagamihara (JUTEM) in collaboration with United Nations/Japan Long-term Fellowship Program 2014. Many thanks to Okuyama laboratory especially for using those facilities. This study cannot be completed without the effort and co-operation from team. I would like to express my gratitude to the student's respondents for the support and willingness.

\section{References}

[1] Neha Mehra, Rajesh K. Singh, and Subhash C. Bera. "MITIGATION OF COMMUNICATION BLACKOUT DURING RE-ENTRY USING STATIC MAGNETIC FIELD." Progress in Electromagnetics Research, Vol. 63, 161-172, 201.

[2] Bianca SZASZ, Keiichi OKUYAMA, Sumio KATO and Takayuki Shimoda. "EMPIRICAL STUDY OF THE LIGHTWEIGHT ABLATOR SERIES FOR TRANSFER VEHICLE SYSTEMS (LATS).” Trans. JSASS Aerospace Tech. Japan, Vol. 14, No. ists30, pp. Pe_41Pe_47, 2016.

[3] Keiichi Okuyama, Teruhiko Kanada, Sumio Kato, Takeharu Sakai, Toshiyuki Suzuki, Kazuhisa Fujita and Seiji Nishio. "THERMOCHEMICAL AND THERMOMECHANICAL CHARACTERISTICS OF AN ULTRA LIGHTWEIGHT CFRP UNDER HIGH TEMPERATURE ENVIRONMENTS.” 2011-c-15, International Symposium on Space Technology and Science, Okinawa, Japan, June 5-10, 2011. 
[4] Bianca SZASZ, Keiichi OKUYAMA. "A NEW METHOD FOR ESTIMATING THE MASS RECESSION RATE FOR ABLATOR SYSTEMS.” World Academy of Science, Engineering and Technology International Journal of Mechanical, Aerospace, Industrial, Mechatronic and Manufacturing Engineering Vol. 8, No. 11, 2014.

[5] Tetsuya Yamada and Toshifumi Inatani. ARC HEATING FACILITY AND TEST TECHNIQUE FOR PLANETARY ENTRY MISSION. The Institute of Space and Astronautical Science, Repot SP No. 17 March 2003.

[6] Takayuki Shimoda and Kazuhiko Yamada.Dgfsdgs. ARC HEATING WIND TUNNEL FACILITY IN ISAS/JAPAN AND THE ACTIVITY TO UPDATE AND IMPROVE IT FOR FURTHER SAMPLE RETURN MISSIONS. 46th International Conference on Environmental Systems ICES-2016-078 10-14 July 2016, Vienna, Austria.

[7] Masumoto Hiroki. JAPAN ULTRA-HIGH TEMPERATURE MATERIALS RESEARCH CENTER AND RESEARCH ACTIVITIES OF JAPAN ULTRA-HIGH TEMPERATURE MATERIALS RESEARCH INSTITUTEMISSIONS. Gas Turbine Society, Bulletin of GSTJ 2000.

[8] http://www.jutem-gifu.jp/category/2023886.html.

*Corresponding author.

E-mail address: 0595904a@mail.kyutech.jp 